\title{
The VEGF/VEGF-R Axis in Sporadic Vestibular Schwannomas Correlates with Irradiation and Disease Recurrence
}

\author{
D. Koutsimpelas ${ }^{\mathrm{a}} \quad$ M. Bjelopavlovic ${ }^{\mathrm{a}}$ R. Yetis ${ }^{\mathrm{a}} \quad$ K. Frauenknecht $^{\mathrm{b}} \quad$ B. Adryan ${ }^{\mathrm{d}}$
}

\author{
I. Schmidtmann ${ }^{\mathrm{C}}$ H. Gouveris ${ }^{\mathrm{a}} \quad$ K. Fruth ${ }^{\mathrm{a}} \quad$ U.R. Heinrich ${ }^{\mathrm{a}}$ R.H. Stauber ${ }^{\mathrm{a}}$
}

W.J. Mann ${ }^{\mathrm{a}} \quad$ J. Brieger ${ }^{\mathrm{a}}$

${ }^{a}$ Department of Otorhinolaryngology, Head and Neck Surgery, ${ }^{b}$ Department of Neuropathology and ${ }^{\mathrm{C}}$ Institute for Medical Biostatistics, Epidemiology and Informatics, University Medical Center of the Johannes Gutenberg

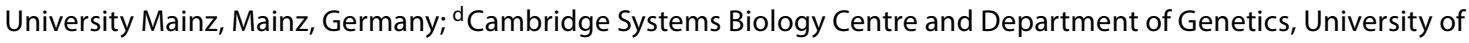
Cambridge, Cambridge, UK

\section{Key Words \\ Vestibular schwannoma - Vascular endothelial growth factor - Vascular endothelial growth factor receptors . Neuropilin $1 \cdot$ Proliferative activity $\cdot$ Irradiation}

\begin{abstract}
Background/Aims: The molecular mechanisms downstream of mutated neurofibromatosis type 2 (NF2) gene resulting in the growth and development of vestibular schwannoma (VS) are controversial. Several lines of evidence suggest the involvement of the vascular endothelial growth factor (VEGF) pathway in VS development. Given that recent studies of VEGF blockade in patients with NF2-associated VS showed positive effects on VS growth control, we initiated this comprehensive study of the VEGF pathway in sporadic VS. Methods: A tissue microarray analysis of 182 sporadic VS was conducted. The expression of VEGF and its receptors as well as the proliferative activity of the tumors were quantified. The expression data were correlated to tumor volumes and diameters as well as to tumor recurrence and previous irradiation. Results: All studied tumors expressed VEGF and its receptors. Proliferative activity was related to the growth characteristics of the tumors. Moreover, we found signifi-
\end{abstract}

cantly higher VEGF levels in recurrent tumors $(p=0.0387)$ and in preoperatively irradiated tumors $(p=0.0213)$. Conclusion: Our data suggest a relevant role of the VEGF pathway in VS growth and therapy outcome. Therefore, targeting this pathway using antiangiogenic compounds might be beneficial for patients with sporadic VS, especially those with recurrent or irradiated tumors.

Copyright $\odot 2012$ S. Karger AG, Basel

\section{Introduction}

Vestibular schwannomas (VS) are rare, slow-growing neoplasms that occur as a result of increased uncontrolled proliferation of the Schwann cells of the vestibular branch of the VIIIth cranial nerve. They are typically well circumscribed and encapsulated by epineurium. Mutations of the neurofibromatosis type 2 (NF2) gene are the main cause of VS genesis in both familial and sporadic schwannomas [1]. Nevertheless, further VS growth shows diverse growth patterns. VS may grow continuously or only up to a certain size, followed by stagnation or even shrinkage [2]. Progressive growth eventually leads to displacement and/or pressure of neighboring neural struc-

Dr. Dimitrios Koutsimpelas

Department of Otorhinolaryngology, Head and Neck Surgery

University Medical Center of the Johannes Gutenberg University Mainz

Langenbeckstrasse 1, DE-55101 Mainz (Germany)

E-Mail karger@karger.com Accessible online at:

www.karger.com www.karger.com/orl 
tures without direct invasion, necessitating therapeutic intervention.

Vascularization and new blood vessel development are an important aspect of solid tumor growth in general [3] and have also been involved in the specific case of VS growth [4-7]. Among the numerous proangiogenic growth factors, the vascular endothelial growth factor (VEGF) is considered to be a major regulator of angiogenesis. VEGF functions are largely mediated through three receptors, the VEGF receptor 1 (VEGFR-1/Flt), VEGF receptor 2 (VEGFR-2/Flk), and Neuropilin 1 (NP1) $[8,9]$. VEGFR-1/Flt and VEGFR-2/Flk are expressed by Schwann cells, and VEGF has been found to act as a survival factor in these cells [10]. NP1 is a $120-$ to $130-\mathrm{kDa}$ single-spanning transmembrane glycoprotein, initially characterized as a neuronal receptor for semaphorin, and more recently recognized as a VEGF coreceptor $[9,11]$.

Besides its proangiogenic properties, VEGF also has cytoprotective activities [8, 12-14]. Tumor cell resistance to apoptosis induction due to cellular distress induced by irradiation or chemotherapy is increased after VEGF stimulation $[15,16]$.

Given the promising results of the clinical application of anti-VEGF active compounds in patients with NF2associated VS [5, 17], a comprehensive analysis of the VEGF pathway in sporadic VS was warranted to provide a molecular basis for an antiangiogenic treatment decision.

In the present report we present our comprehensive analysis of VEGF, VEGFR-1, VEGFR-2, and NP1 expression in the tumor specimens of 182 sporadic VS patients.

\section{Materials and Methods}

\section{Patients/Specimens}

A total of 182 consecutive adult patients with solitary, sporadic, unilateral VS operated on at the Department of Otorhinolaryngology, University Medical Center of the Johannes Gutenberg University Mainz, Germany, during the years 2000-2007 were included in this study. The median age was 52 years (range 18-78); 79 patients were male and 103 female. Thirteen patients had already been treated prior to operation with stereotactic radiosurgery but still experienced tumor progress, while another 19 patients presented with recurrent tumors after operation. MRI scanning images were used for calculating the tumor diameters (d1, anteroposterior; d2, lateromedial; d3, rostrocaudal). In 24 tumors the rostrocaudal diameter was not obtainable from the MRI scanning images, and the geometrical mean of $\mathrm{d} 1$ and $\mathrm{d} 2$ was used as an estimate of this dimension. The maximum tumor diameter was used for statistical analysis. For calculation of the tumor volumes, we used the following equation, assuming an ellipsoid tumor shape: volume $=1 / 6 \times[\pi] \times \mathrm{d} 1 \times \mathrm{d} 2 \times \mathrm{d} 3$. The specimens obtained in the operation room were fixed in formalin for $24 \mathrm{~h}$, paraffin embedded, and used for later immunohistochemical analysis. This study was performed in accordance with the ethical standards laid down in the 1964 Declaration of Helsinki and its later amendments. The study was approved by the institutional review board and informed consent was given by the patients prior to analysis.

\section{Tissue Microarray}

Tissue microarrays were created from the resected tumor specimens. In short, paraffin-embedded tumor material was cut into $4-\mu \mathrm{m}$-thick sections and stained with hematoxylin/eosin. Representative areas were chosen, and biopsies of 5-mm diameter were taken from the donor block and included in recipient tissue array blocks using a precision tissue array instrument (TissueTEK $^{\circledR}$ Quick-Ray ${ }^{\mathrm{TM}}$; Sakura Finetek USA Inc., Torrance, Calif., USA). From this tissue array block 4 - $\mu$ m-thick sections were prepared for further immunohistochemical analysis.

\section{Immunohistochemistry}

Immunohistochemical analysis was performed using standard procedures. In brief, dewaxing and rehydration followed by blocking of endogenous peroxidase with $3 \% \mathrm{H}_{2} \mathrm{O}_{2}$ /methanol was carried out. After preincubation with $10 \%$ normal serum in $2 \%$ bovine serum albumin/phosphate-buffered saline (PBS) for 20 min to avoid unspecific binding, primary antibodies (VEGF sc152, 1:200; VEGFR-1/Flt-1 sc-316, 1:150; VEGFR-2/Flk-1 sc-6251, 1:100; NP1 sc-5307, 1:75; Santa Cruz Biotechnology Inc., Santa Cruz, Calif., USA; Ki-67 M7240, 1:200; DAKO A/S, Glostrup, Denmark) were overlaid overnight at $4^{\circ} \mathrm{C}$. Slides were then incubated with goat anti-mouse or goat anti-rabbit biotinylated secondary antibody (E0433, 1:250; E0432, 1:250; DAKO A/S) and streptavidin/HRP (P0397, 1:100; DAKO A/S). All washing procedures were performed in PBS. Slides were counterstained with hematoxylin. Negative controls were performed, substituting the primary antibody with PBS. Normal kidney tissue served as positive control.

\section{Quantification of the Expression}

For evaluation of the VEGF, VEGFR-1, VEGFR-2, and NP1 expression the stained area and intensity of each section in five fields were measured by a computer-based image analysis method, as described in detail previously $[18,19]$. In brief, three representative areas (400× magnification, corresponding to $25 \times 25$ $\mu \mathrm{m})$ of each tissue sample were documented in .jpg using an inverted microscope (Zeiss, Jena, Germany). For quantification, the .jpg documents were analyzed using Photoshop (Adobe Systems Inc., San Jose, Calif., USA). The stainings were quantified by the multiplication of the stained area by the staining intensity and expressed as arbitrary units (AU). This method allows relative comparison of expression levels. Computer-based image analysis was performed by the same researcher (M.B.) for minimum variability and later confirmed by a second scientist (U.R.H.) in a blinded fashion.

\section{Proliferative Activity}

Using a light microscope we evaluated five areas of the stained sections at 400 -fold magnification. At least 500 cells were evaluated per section and the mean percentage of the Ki- 67 positive tumor cells was calculated. 
Statistics

The Wilcoxon rank sum test was used to assess whether differences between two groups were significant. Pearson's product moment correlation was used for statistical data evaluation, with $\mathrm{p}<0.05$ as the level of significance. Data shown are mean values \pm SD. All calculations were performed using the SPSS 15.0 (SPSS, Inc., Chicago, Ill., USA). Data were not adjusted for multiple testing because of the explorative nature of the study.

Hierarchical clustering of the tumors was performed based on their expression of VEGF, VEGFR-1, VEGFR-2, NP1, proliferative index, tumor volume and diameter. The values for each parameter were normalized and the deviation from the mean was color coded (blue $>$ mean, yellow < mean). We used k-means clustering with 3 groups in Genesis v1.75 to derive three biologically distinct groups [20]. The selection of three groups was motivated by a previous hierarchical clustering approach that allowed us to identify the largest grouping visually.

\section{Results}

In total, 182 patients (age $52 \pm 10.6$ years; range $18-78$ ) were studied. Tumor volume varied between 24 and $37,679 \mathrm{~mm}^{3}$ (mean 2,404 $\pm 2,329$ ) while the maximum tumor diameter ranged between 3.2 and $41 \mathrm{~mm}$ (mean $15.73 \pm 8.82$ ). The proliferation index ranged between 0.1 and $2.5 \%$ (mean $0.91 \pm 0.54$ ). Representative immunohistochemical stainings are shown in figure 1.

By using the VEGF antibody, cytoplasmic staining of the tumor and endothelial cells was observed (fig. 1). VEGF expression varied from 1.26 to 5,025 AU (mean 570 \pm 497 ). The VEGF-receptors were expressed on the cell membrane as expected (fig. 1). Expression of VEGFR-1/ Flt varied between a minimum of $14 \mathrm{AU}$ and a maximum of 3,483 AU (mean $875 \pm 604$ ), VEGFR-2/Flk between 23 and 1,723 AU (mean $573 \pm 379$ ), and NP1 between a minimum of $61 \mathrm{AU}$ and a maximum of 1,924 AU (mean 494 \pm 252 ).

We found a significant positive correlation of VEGFR-2 expression to both VEGFR-1 and NP1 expression, and a significant positive correlation of the proliferation index to the tumor volume and tumor diameter (fig. 2a-e). Nonetheless, no correlation between VEGF expression and VEGFR-1, VEGFR-2 or NP1 expression was observed (data not shown). The age of the patients did not correlate with the results of the immunohistochemical quantification or with the tumor growth characteristics. Expression of neither VEGF nor its receptors correlated with the proliferation indexes or the growth characteristics of the tumors.

Interestingly, significantly increased VEGF levels were found in the groups of recurrent $(\mathrm{p}=0.0387)$ and preop- eratively irradiated tumors $(\mathrm{p}=0.0213)$ when compared to the VEGF levels of the group of primary VS patients (fig. 3, 4). Comparison of these three groups concerning the proliferation indexes, VEGF receptor expression, growth characteristics, and the age of the patients revealed no differences (data not shown).

Finally, we performed hierarchical clustering of the tumors based on their expression of VEGF, VEGFR-1, VEGFR-2, NP1, proliferative index, tumor volume and maximum diameter (fig. 5). The tumors clustered in three distinct groups. The first group comprised of tumors with high proliferative activities and high VEGF, VEGFR-1, VEGFR-2 and NP1 expression combined with large volumes and large diameters $(n=35$; fig. $5 \mathrm{a})$. The second group of tumors showed high proliferative activities and high VEGF, VEGFR-1, VEGFR-2 and NP1 expression but low volumes and small diameters $(n=42$; fig. 5b). The third group comprised of tumors with low proliferative activities and low expression of VEGF and all three receptors as well as low volumes and small diameters ( $\mathrm{n}=105$; fig. $5 \mathrm{c}$ ). Interestingly, the higher percentage of tumors treated with radiation therapy prior to operation was found in the second group of tumors (5/42, $12 \%$; fig. $5 \mathrm{~d}$ ), while the higher percentage of recurrent tumors clustered in the first group of tumors $(8 / 35,23 \%$; fig. 5e).

\section{Discussion}

Despite the initiation of clinical trials evaluating antiangiogenic active compounds for the therapy of familial VS, no large comprehensive analysis of the VEGF pathway in sporadic VS patients has been available until now. We here show that sporadic VS tumor growth is associated with proliferative activity and that tumor VEGF levels are correlated to tumor recurrence and radiation therapy failure.

Angiogenesis is a major prerequisite for the proliferation and progression of several neoplasms [3]. Despite the fact that VS are generally slow-growing tumors, and therefore may not need excessive vascularization for progression, a functional vascular system still remains important for further growth. VEGF is one of the most potent angiogenic factors $[3,8]$ and is expressed in most tumor entities [21]. Pietsch et al. [22] and Nishikawa et al. [23] analyzed several types of brain tumors for VEGF expression and demonstrated this cytokine not only in strongly vascularized brain tumors such as glioblastomas but also in the less vascularized astrocytomas and me- 

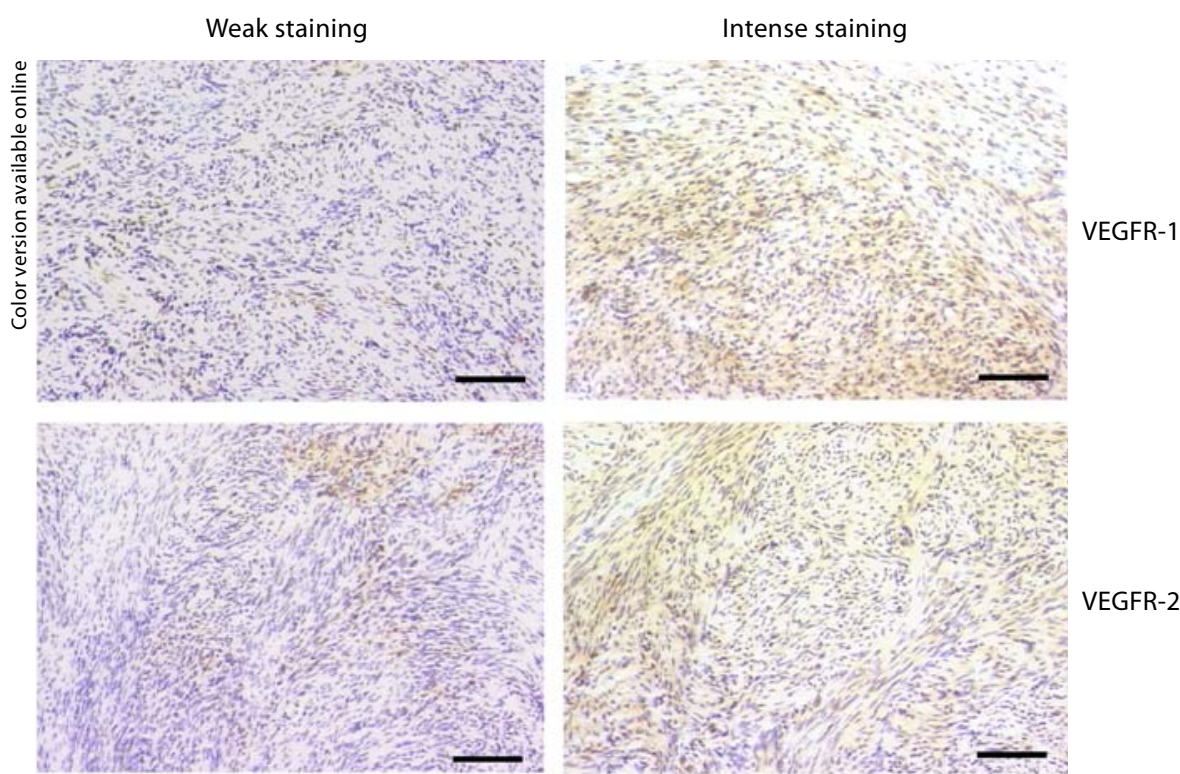

VEGFR-2
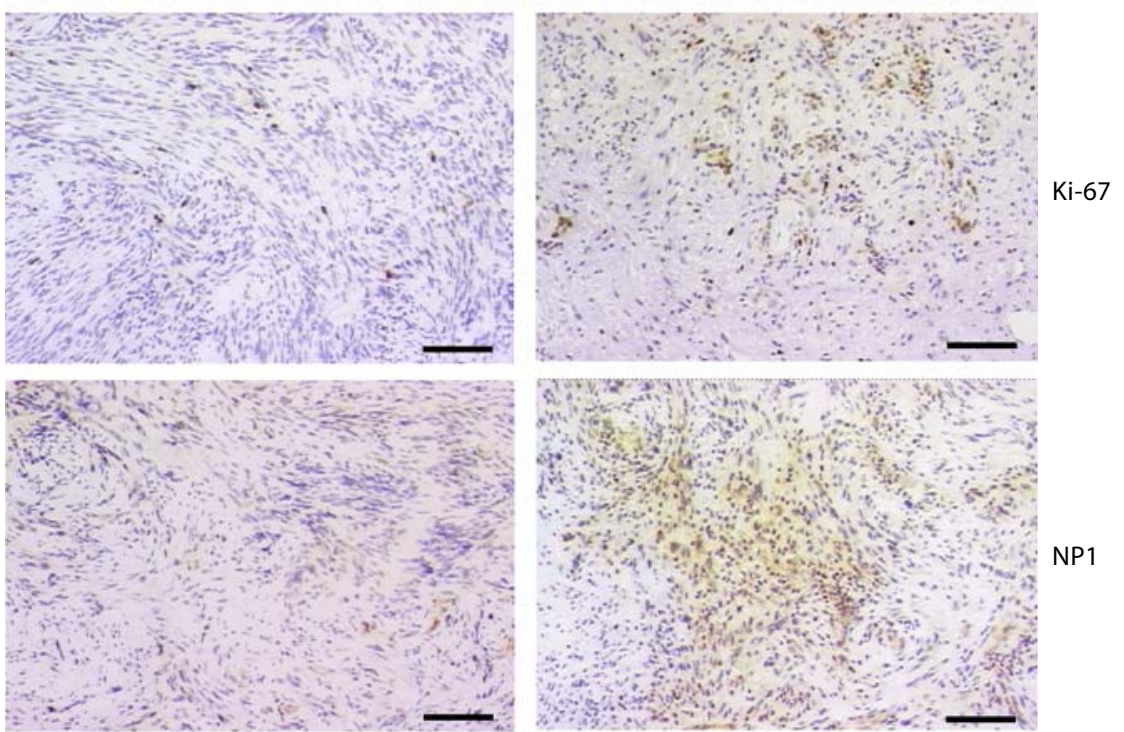

Fig. 1. Representative immunohistochemical stainings of tumor samples showing weak and intense staining for VEGFR-1, VEGFR-2, Ki-67, NP1 and VEGF. Scale bar $=100 \mu \mathrm{m}$.
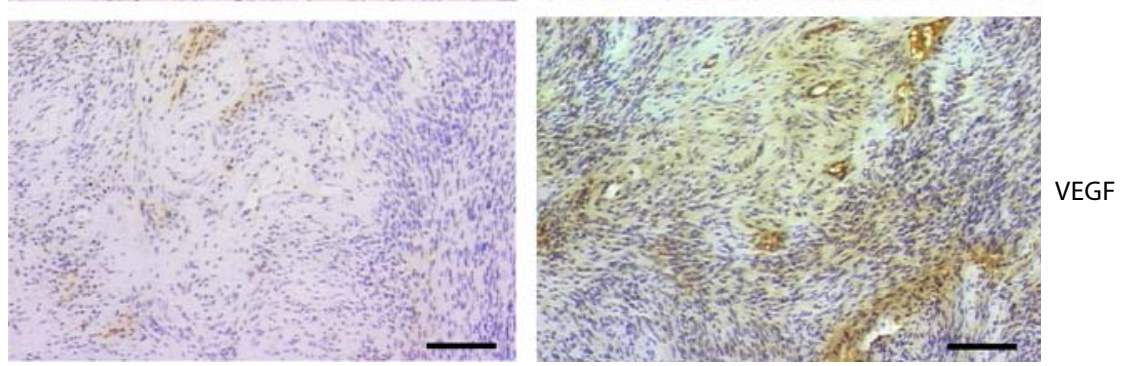

ningiomas. Moreover, VEGF has been reported to act as a survival factor for Schwann cells [10]. Accordingly, upregulated VEGF expression has been previously demonstrated in VS [5, 7, 24-26]. In our present study also, all samples expressed VEGF. Moreover, we found that all of the tumors expressed VEGFR-1/Flt and VEGFR-2/Flk as well as the coreceptor NP1. Expression of VEGF and of all three receptors was identified both on tumor cells and on endothelial cells of tumor-associated vessels, which is in line with previous reports $[5,7,26,27]$. This finding 


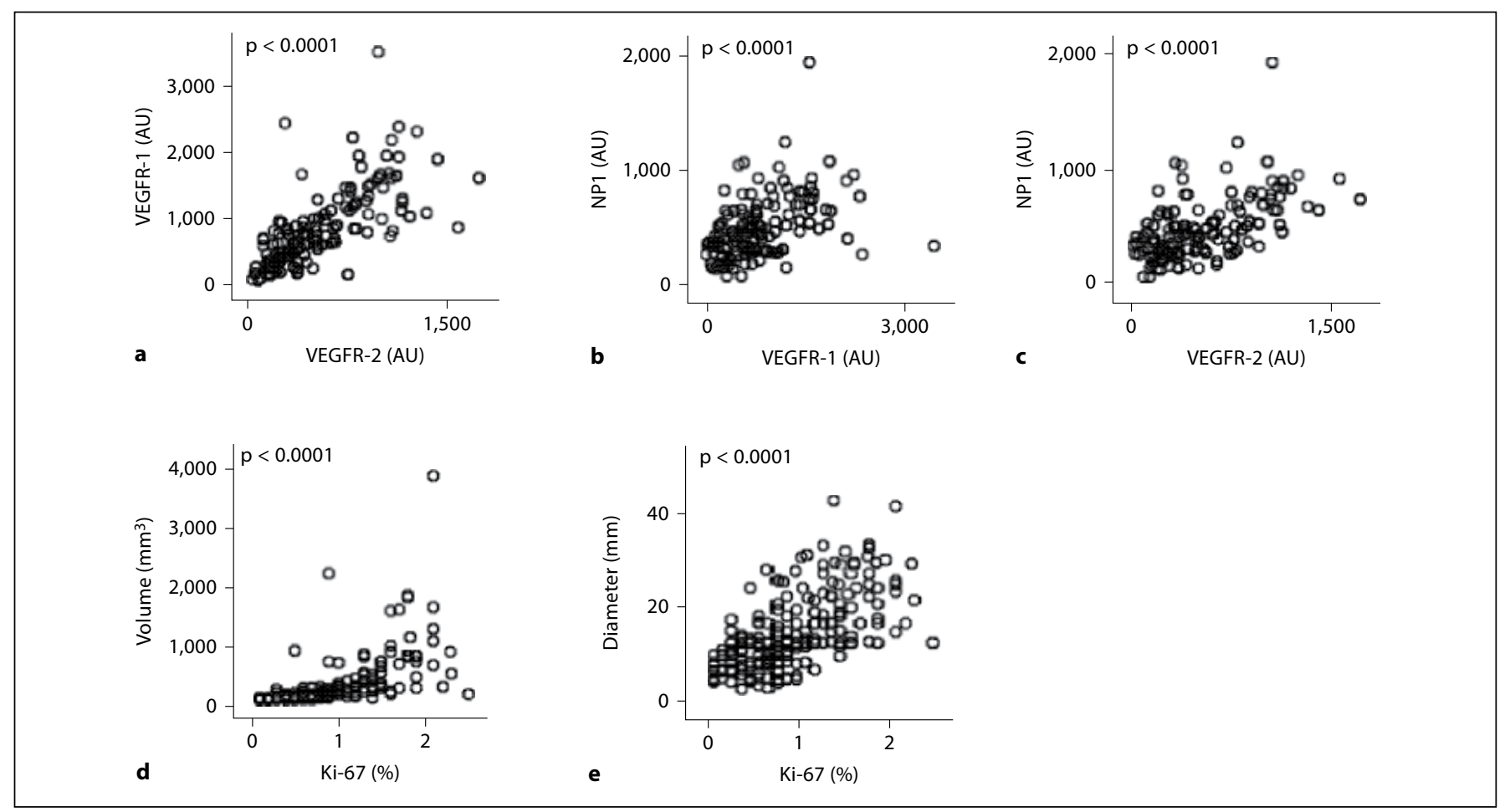

Fig. 2. Scatter plots show a positive correlation between VEGFR-1 and VEGFR-2 expression (a), NP1 and VEGFR-1 expression (b), NP1 and VEGFR-2 expression (c), tumor volume and proliferation index (d), and tumor diameter and proliferation index (e).

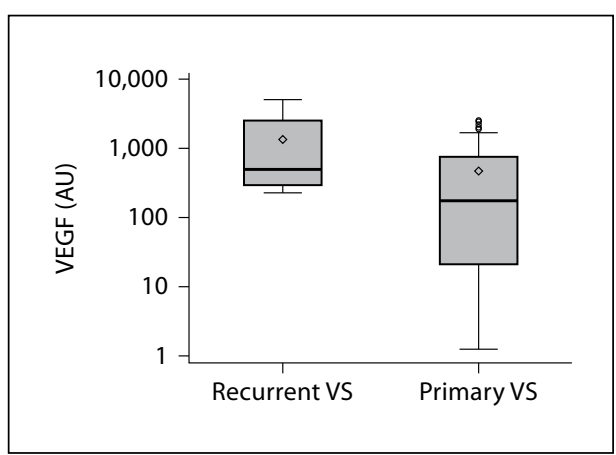

Fig. 3. VEGF expression comparing recurrent and primary tumors. VEGF expression in samples from the recurrent tumors is significantly higher compared to VEGF expression in samples from primary tumors. Differences were calculated by the Wilcoxon rank sum test; ${ }^{\star} \mathrm{p}<0.05$.

may suggest a cross-talk between tumor cells and vessels in a paracrine-stimulating manner.

The available data concerning the proliferative activity of VS are contradictory. In a previous study, large VS exhibited enhanced proliferative activity compared with

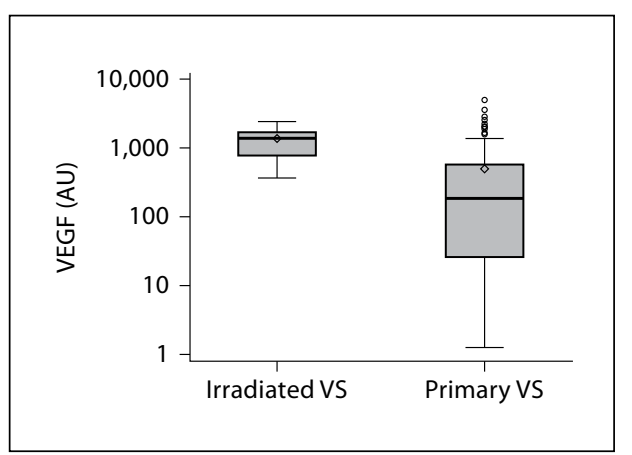

Fig. 4. VEGF expression comparing tumors previously treated with radiation therapy and primary tumors. VEGF expression in samples from tumors irradiated prior to surgery is significantly higher compared to samples from primary tumors. Differences were calculated by the Wilcoxon rank sum test; ${ }^{\star} \mathrm{p}<0.05$.

smaller lesions [28]. Similar results have also been reported by other authors describing a higher proliferative activity in large tumors [29-31]. However, these results have been contradicted by Charabi et al. [32, 33], who found no correlation between tumor size and prolifera- 


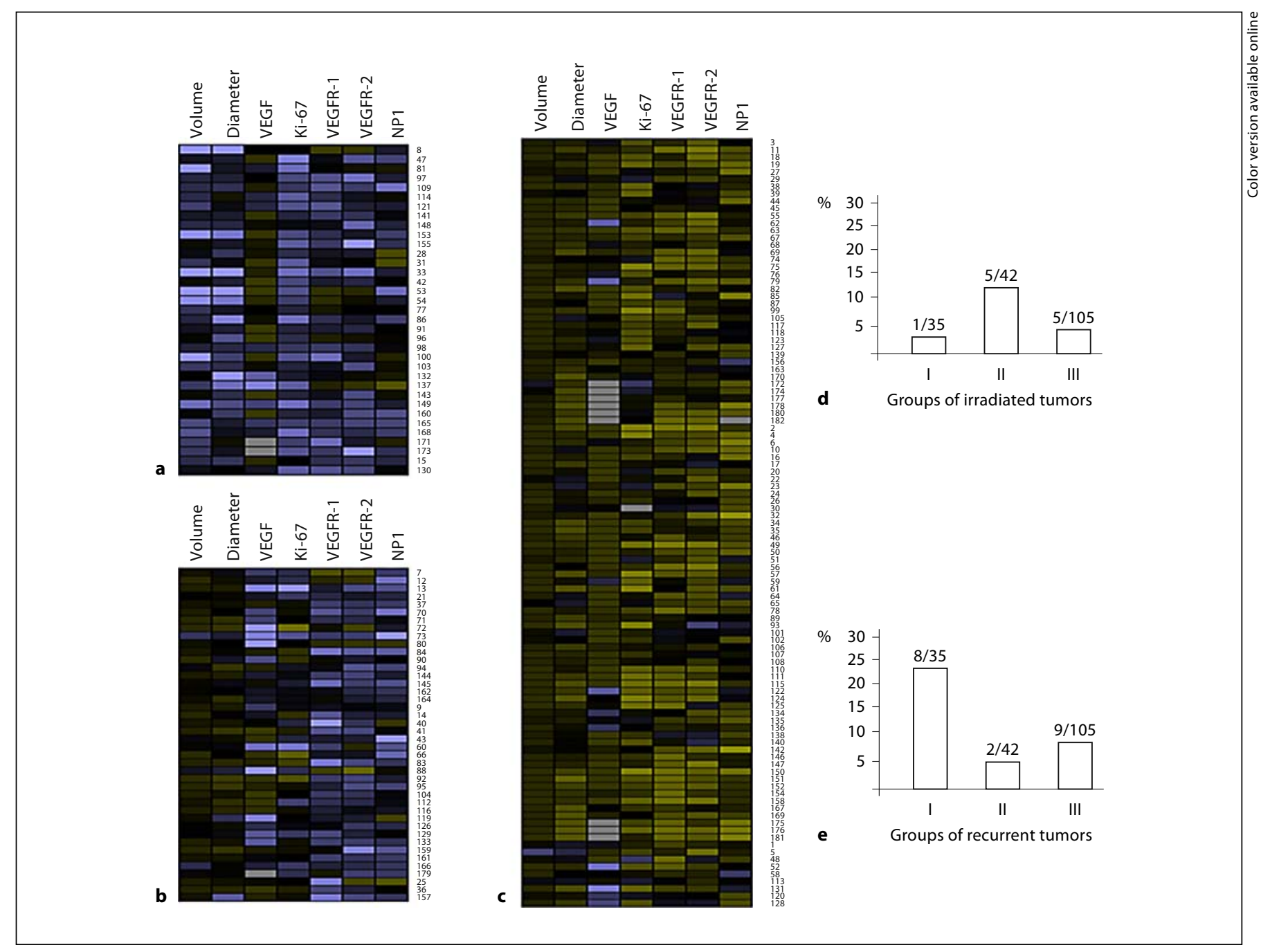

Fig. 5. Hierarchical clustering of VS based on their expression of VEGF, VEGFR-1/Flt, VEGFR-2/Flk, NP1, proliferative index, volume and maximum diameter. The values for each parameter were normalized and the deviation from the mean was color coded (blue $>$ mean, yellow $<$ mean). Tumors were classified into three distinct clusters. a Tumors with large diameters, high volumes, and proliferative activities combined with high VEGF, VEGFR-1, VEGFR-2, and NP1 expression (group I, $\mathrm{n}=35$ ). b Tumors with low volumes and small diameters but high expression of VEGF, VRGFR-1, VEGFR-2, NP1, and high proliferative indexes (group

tive activity. In our current analysis we found relatively low proliferative indexes, as expected for a benign neoplasm. Furthermore, we were able to identify a correlation of proliferative activity to tumor volume and tumor diameter. One possible explanation for these conflicting literature reports is that the assessment of proliferation indexes can be influenced by the point of time when the operation is performed and the tissue becomes available

VEGF and Its Receptors in Vestibular Schwannomas
II, $\mathrm{n}=42)$. c Tumors with small diameters, low volumes, and proliferative activities combined with low VEGF, VEGFR-1, VEGFR-2, and NP1 expression (group III, $\mathrm{n}=105$ ). $\mathbf{d}$ Distribution of the tumors treated by radiation therapy prior to surgery. Previously irradiated tumors clustered more frequently in group II and were associated with high proliferative indexes and high VEGF and VEGF receptor expression. e Distribution of the recurrent tumors. Recurrent tumors clustered more frequently in group I and were associated with high proliferative indexes and high VEGF and VEGF receptor expression.

for analysis, since many VS do not grow continuously but can remain stable over a long period of time [2]. Niemczyk et al. [34] have reported in a study of $12 \mathrm{VS}$ that the group of tumors which had been shown to grow at the time of surgical removal had a higher proliferation index than the group of stable (nongrowing) tumors. A further factor that may influence the value of the assessed $\mathrm{Ki}-67$ index is the exact location of the biopsy tak-
ORL

DOI: $10.1159 / 000346238$ 
en. Szeremeta et al. [35] reported that the highest level of proliferation was found in specimens taken from the capsule of the tumor and that the proliferation activity of specimens taken from the tumor parenchyma was much lower. All these potentially confounding factors become more relevant if small sample numbers are studied. In the present study, a large number of tumors were analyzed and the tissue material used originated from biopsy specimens taken from random tumor sites (hence avoiding these potential biases), suggesting that actually impaired growth-regulating mechanisms are involved in the progression of VS.

Interestingly, the recurrent tumors and the tumors treated with radiosurgery prior to operation showed a considerable elevated VEGF expression in comparison to the primary tumors. In a previous study, Uesaka et al. [27] reported an increased VEGF mRNA expression in recurrent VS, and suggested a possible involvement of VEGF in the growth or recurrence of these tumors. Our data from the present manuscript support these findings. This increased VEGF expression in the recurrent tumors may be the result of surgical trauma or the result of an intrinsic propensity of a subset of VS tumors. Since most of the recurrent VS tumors are tumor persisters, it might be assumed that in patients with tumor persistence after surgical treatment the aforementioned intrinsic propensity might accelerate the clinical/radiological manifestation of recurrence. To further clarify this issue, a comparison between the data regarding VEGF expression of the primary tumor and of the respective data of the recurrent tumor in the same patient would be necessary.

Furthermore, Uesaka et al. [27] reported that two tumors which had undergone radiation therapy before surgery also showed an increased VEGF mRNA expression. The authors hypothesized an upregulation of VEGF mRNA expression by radiation, which has been associated with rapid tumor expansion. Upregulation of VEGF by irradiation has been previously reported in a variety of neoplasms [36-39]. The present data from our large-scale study support the hypothesis that irradiation of VS might lead to an upregulation of VEGF, which in the long term might be associated with progress of a residual tumor. However, a further point has to be addressed concerning the increased VEGF expression in the group of irradiated tumors. It has been previously reported that both endothelial cells of epithelial tumors and tumor cells themselves found under cellular distress might be protected by VEGF $[12,15,16]$. A similar effect of VEGF has been reported in glioblastoma cell lines [13]. In our study we found increased VEGF expression in the group of irradiated tumors. This group included tumors which have shown progress after the radiation treatment and therefore have been surgically removed. It might be possible that these tumors express high levels of VEGF per se. These increased VEGF levels might contribute to the protection of the endothelial and/or tumor cells during the radiation. Therefore, we hypothesize that a VEGF-mediated protection of VS endothelial and/or tumor cells might be a mechanism resulting in different radiation sensitivity. Consequently, the failure of radiation therapy to control VS tumors might depend on high VEGF expression levels. Whether these tumors express increased VEGF per se, or the increased VEGF expression is an epiphenomenon resulting from the radiation, remains unclear. A future in vitro study investigating further the association of radiation therapy with the expression of VEGF in VS will be the obvious extension of the present investigation.

Furthermore, cluster analysis revealed that in the group of VS patients with irradiated tumors, tumors with high proliferative indexes expressing high levels of VEGF and its receptors were more frequently observed than tumors with low proliferative activity and low VEGF and VEGF receptor expression. Similar results were observed for the recurrent tumors, suggesting that the VEGF pathway is of relevance for the proliferation of recurrent and irradiated tumors.

These data are of potential clinical relevance given that recent studies of VEGF blockade with bevacizumab in patients with NF2-associated VS showed a reduction in the volume of most VS $[5,17]$. This has been attributed primarily to tumor shrinkage due to changes in intratumoral vascular permeability and subsequently due to the reduction of the intratumoral edema as well as to increased tumor cell death through the antivascular effect $[5,6,17]$.

Since sporadic VS express VEGF and its receptors, targeting this pathway may be beneficial on a clinical basis. Our cluster analysis suggests that patient selection according to molecular tumor characteristics and associated clinical features may be feasible and lead to individualized targeted therapy of VS patients. From a clinical perspective, recurrent tumors might be targeted using antiangiogenic active compounds. Moreover, if VEGFmediated VS protection through reduction of radiation sensitivity were proved, then a combination of radiation therapy and anti-VEGF treatment (especially in VS patients with high intratumoral VEGF levels) might improve treatment outcome. 


\section{Acknowledgments}

We thank Karin Backes for her technical expertise.

This work was funded by a grant provided by the Head and Neck Tumor Research Foundation, Wiesbaden, Germany. The foundation is a nonprofit organization. The funders played no role in the experiment design, execution, analysis or preparation of the paper.

\section{Disclosure Statement}

The authors have no conflicts of interest to declare.

\section{References}

1 Irving RM, Moffat DA, Hardy DG, Barton DE, Xuereb JH, Maher ER: Somatic NF2 gene mutations in familial and non-familial vestibular schwannoma. Hum Mol Genet 1994;3:347-350.

-2 Charabi S: Acoustic neuroma/vestibular schwannoma in vivo and in vitro growth models. A clinical and experimental study. Acta Otolaryngol 1997;530(suppl):1-27.

3 Folkmann J: Tumor angiogenesis: therapeutic implications. N Engl J Med 1971;285: 1182-1186.

4 Møller MN, Werther K, Nalla A, Stangerup SE, Thomsen J, Bøg-Hansen TC, Nielsen HJ, Cayé-Thomasen P: Angiogenesis in vestibular schwannomas: expression of extracellular matrix factors MMP-2, MMP-9, and TIMP-1. Laryngoscope 2010;120:657-662.

5 Plotkin SR, Stemmer-Rachamimov AO, Barker FG 2nd, Halpin C, Padera TP, Tyrrell A, Sorensen AG, Jain RK, di Tomaso E: Hearing improvement after bevacizumab in patients with neurofibromatosis type $2 . \mathrm{N}$ Engl J Med 2009;361:358-367.

6 Wong HK, Lahdenranta J, Kamoun WS, Chan AW, McClatchey AI, Plotkin SR, Jain RK, di Tomaso E: Anti-vascular endothelial growth factor therapies as a novel therapeutic approach to treating neurofibromatosisrelated tumors. Cancer Res 2010;70:34833493.

7 Koutsimpelas D, Stripf T, Heinrich UR, Mann WJ, Brieger J: Expression of vascular endothelial growth factor and basic fibroblast growth factor in sporadic vestibular schwannomas correlates to growth characteristics. Otol Neurotol 2007;228:1094-1099.

8 Ferrara N, Gerber HP, Le Couter J: The biology of VEGF and its receptors. Nat Med 2003;9:669-676.

-9 Staton CA, Kumar I, Reed MW, Brown NJ: Neuropilins in physiological and pathological angiogenesis. J Pathol 2007;212:237-248.

10 Schratzberger P, Schratzberger G, Silver M,
Curry C, Kearney M, Magner M, Alroy J, Adelman LS, Weinberg DH, Ropper AH, Isner JM: Favorable effect of VEGF gene transfer on ischemic peripheral neuropathy. Nat Med 2000;6:405-413.

$\checkmark 11$ He Z, Tessier-Lavigne M: Neuropilin is a receptor for the axonal chemorepellent semaphorin III. Cell 1997;90:739-751.
12 Brieger J, Kattwinkel J, Berres M, Gosepath J, Mann WJ: Impact of vascular endothelial growth factor release on radiation resistance. Oncol Rep 2007;18:1597-1601.

$\checkmark 13$ Hovinga KE, Stalpers LJ, van Bree C, Donker M, Verhoeff JJ, Rodermond HM, Bosch DA, van Furth WR: Radiation-enhanced vascular endothelial growth factor (VEGF) secretion in glioblastoma multiforme cell lines - a clue to radioresistance? J Neurooncol 2005; 74:99-103.

14 Harmey JH, Bouchier-Hayes D: Vascular endothelial growth factor (VEGF), a survival factor for tumour cells: implications for antiangiogenic therapy. Bioessays 2002;24:280283.

15 Gorski DH, Beckett MA, Jaskowiak NT, Calvin DP, Mauceri HJ, Salloum RM, Seetharam S, Koons A, Hari DM, Kufe DW, Weichselbaum RR: Blockage of the vascular endothelial growth factor stress response increases the antitumor effects of ionizing radiation. Cancer Res 1999;59:3374-3378.

16 Brieger J, Schroeder P, Gosepath J, Mann WJ: VEGF subtype-specific protection of SCC and HUVECs from radiation induced cell death. Int J Mol Med 2005;15:145-151.

17 Mautner VF, Nguyen R, Knecht R, Bokemeyer C: Radiographic regression of vestibular schwannomas induced by bevacizumab treatment: sustain under continuous drug application and rebound after drug discontinuation. Ann Oncol 2010;21:2294-2295.

18 Gosepath J, Brieger J, Lehr HA, Mann WJ: Expression, localization and significance of vascular permeability/vascular endothelial growth factor in nasal polyps. Am J Rhinol 2005;19:7-13.

19 Heinrich UR, Brieger J, Selivanova O, Feltens R, Eimermacher A, Schäfer D, Mann WJ: COX-2 expression in the guinea pig cochlea is partly altered by moderate sound exposure. Neurosci Lett 2006;394:121-126.

20 Sturn A, Quackenbush J, Trajanoski Z: Genesis: cluster analysis of microarray data. Bioinformatics 2002;18:207-208.

21 Ferrara N, Davis-Smyth T: The biology of vascular endothelial growth factor. Endocr Rev 1997;18:4-25.
22 Pietsch T, Valter MM, Wolf HK, von Deimling A, Huang HJ, Cavenee WK, Wiestler OD: Expression and distribution of vascular endothelial growth factor protein in human brain tumors. Acta Neuropathol 1997;93: 109-117.

23 Nishikawa R, Cheng SY, Nagashima R, Huang HJ, Cavenee WK, Matsutani M: Expression of vascular endothelial growth factor in human brain tumors. Acta Neuropathol 1998;96:453-462.

24 Dalgorf DM, Rowsell C, Bilbao JM, Chen JM: Immunohistochemical investigation of hormone receptors and vascular endothelial growth factor concentration in vestibular schwannoma. Skull Base 2008;18:377-384.

25 Saito K, Kato M, Susaki N, Nagatani T, Nagasaka T, Yoshida J: Expression of Ki-67 antigen and vascular endothelial growth factor in sporadic and neurofibromatosis type 2 -associated schwannomas. Clin Neuropathol 2003;22:30-34.

26 Cayé-Thomasen P, Werther K, Nalla A, BøgHansen TC, Nielsen HJ, Stangerup SE, Thomsen J: VEGF and VEGF receptor-1 concentration in vestibular schwannoma homogenates correlates to tumor growth rate. Otol Neurotol 2005;26:98-101.

27 Uesaka T, Shono T, Suzuki SO, Nakamizo A, Niiro H, Mizoguchi M, Iwaki T, Sasaki T: Expression of VEGF and its receptor genes in intracranial schwannomas. I Neurooncol 2007;83:259-266.

28 Bedavanija A, Brieger J, Lehr HA, Maurer J, Mann WJ: Association of proliferative activity and size in acoustic neuroma: implications for timing of surgery. J Neurosurg 2003;98:807-811.

29 Lesser TH, Janzer RC, Kleihues P, Fisch U: Clinical growth rate of acoustic schwannomas: correlation with the growth fraction as defined by the monoclonal antibody Ki- 67 . Skull Base Surg 1991;1:11-15.

30 Wiet RJ, Ruby SG, Bauer GP: Proliferating cell nuclear antigen in the determination of growth rates in acoustic neuromas. Am J Otol 1994;15:294-298.

31 Fucci MJ, Buchman CA, Brackmann DE, Berliner KI: Acoustic tumor growth: implications for treatment choices. Am J Otol 1999;20:495-499.
VEGF and Its Receptors in Vestibular Schwannomas
ORL 
32 Charabi S, Engel P, Charabi B, Jacobsen GK, Overgaard J, Thomsen J, Tos M: Growth of vestibular schwannomas: in situ model employing the monoclonal antibody $\mathrm{Ki}-67$ and DNA flow cytometry. Am J Otol 1996;17: 301-306, erratum p 692.

- 33 Charabi S, Engel P, Jacobsen GK, Tos M, Thomsen J: Growth rate of acoustic neuroma expressed by $\mathrm{Ki}-67$ nuclear antigen versus symptom duration. Ann Otol Rhinol Laryngol 1993;102:805-809.

34 Niemczyk K, Vaneecloo FM, Lecomte MH, Lejeune JP, Lemaitre L, Skarzyński H, Vincent C, Dubrulle F: Correlation between Ki67 index and some clinical aspects of acoustic neuromas (vestibular schwannomas). Otolaryngol Head Neck Surg 2000;123:779783.
5 Szeremeta W, Monsell EM, Rock JP, Caccamo DV: Proliferation indices of vestibular schwannomas by Ki- 67 and proliferating cell nuclear antigen. Am J Otol 1995; 16:616-619.

36 Wachsberger P, Burd R, Dicker AP: Tumor response to ionizing radiation combined with antiangiogenesis or vascular targeting agents: exploring mechanisms of interaction. Clin Cancer Res 2003;9:1957-1971.
37 Steiner HH, Karcher S, Mueller MM, Nalbantis E, Kunze S, Herold-Mende CJ: Autocrine pathways of the vascular endothelial growth factor (VEGF) in glioblastoma multiforme: clinical relevance of radiation-induced increase of VEGF levels. J Neurooncol 2004;66:129-138.

38 Artman T, Schilling D, Gnann J, Molls M, Multhoff G, Bayer C: Irradiation-induced regulation of plasminogen activator inhibitor type-1 and vascular endothelial growth factor in six human squamous cell carcinoma lines of the head and neck. Int J Radiat Oncol Biol Phys 2010;76:574-582.

-39 Nozue M, Isaka N, Fukao K: Over-expression of vascular endothelial growth factor after preoperative radiation therapy for rectal cancer. Oncol Rep 2001;8:1247-1249. 